\title{
Pengaruh Ekspektasi Pengembalian, Toleransi Risiko, Dan Efikasi Diri Terhadap Minat Investasi Saham
}

\author{
Frans dan Sarwo Edy Handoyo \\ Program Studi Manajemen Fakultas Ekonomi Universitas Tarumanagara, Jakarta \\ Email:franskristof@gmail.com
}

\begin{abstract}
The purpose of this research is to examine the influence of expected return, risk tolerance, and self-efficacy toward stock investment intention. Sample collection was conducted using the Google Form online questionnaire with a purposive sampling, type of non-probability sampling method, with a total of 100 respondents from the Faculty of Economics and Business, Universitas Tarumanagara, Jakarta. Data processing is done by PLS-SEM method and analyzed with SmartPLS 3.2.8. The results of this study indicate that expected return and risk tolerance have a significant positive effect on stock investment intention. Whereas, self-efficacy does not have a significant effect.
\end{abstract}

Keywords: Expected Return, Risk Tolerance, Self-Efficacy, Stock Investment Intention.

\begin{abstract}
Abstrak: Tujuan penelitian ini adalah untuk mengetahui pengaruh ekspektasi pengembalian, toleransi risiko, dan efikasi diri terhadap minat investasi saham. Pengumpulan sampel dilakukan dengan menggunakan kuesioner online Google Form dengan metode non-probability sampling berjenis purposive sampling dengan total 100 responden mahasiswa Fakultas Ekonomi dan Bisnis, Universitas Tarumanagara Jakarta. Pengolahan data dilakukan dengan metode PLS-SEM dan dianalisis dengan SmartPLS 3.2.8. Hasil penelitian ini menunjukan bahwa ekspektasi pengembalian dan toleransi risiko memiliki pengaruh positif signifikan terhadap minat investasi saham. Sedangkan, efikasi diri tidak memiliki pengaruh yang signifikan.
\end{abstract}

Kata kunci: Ekspektasi Pengembalian, Toleransi Risiko, Efikasi Diri, Minat Investasi Saham. 


\section{LATAR BELAKANG}

Manusia dalam hidupnya menginginkan pendapatan yang besar agar dapat memenuhi segala kebutuhan dan keinginannya yang sangat beragam dan tidak terbatas. Namun pendapatan yang didapatkan seringkali tidak cukup karena dihabiskan seluruhnya untuk memenuhi kebutuhan maupun keinginan yang selalu muncul dan sifatnya tidak mendesak. Perilaku demikian dapat disebut sebagai perilaku konsumtif. Perilaku ini sangat umum terjadi bagi orang yang baru saja memasuki dunia kerja dan mendapatkan penghasilannya sendiri. Ini diperkuat oleh Survei Manulife Investor Sentiment Index (2016), mengungkapkan 53\% penduduk Indonesia menghabiskan $70 \%$ dari penghasilan mereka untuk belanja, dan 10\% dari penduduk Indonesia bahkan menghabiskan $90 \%$ dari penghasilannya untuk belanja.

Tabel 1.

Jumlah Penduduk dan Investor

\begin{tabular}{|c|c|c|}
\hline Tahun & $\begin{array}{c}\text { Jumlah } \\
\text { Penduduk }\end{array}$ & $\begin{array}{c}\text { Jumlah } \\
\text { Investor }\end{array}$ \\
\hline 2012 & $245,400,000$ & 281,256 \\
\hline 2013 & $248,800,000$ & 320,506 \\
\hline 2014 & $252,200,000$ & 364,465 \\
\hline 2015 & $255,500,000$ & 434,107 \\
\hline 2016 & $258,700,000$ & 894,116 \\
\hline 2017 & $261,900,000$ & $1,122,668$ \\
\hline 2018 & $265,000,000$ & $1,617,367$ \\
\hline
\end{tabular}

Sumber: PT KSEI (2018) dan BPS (2018)

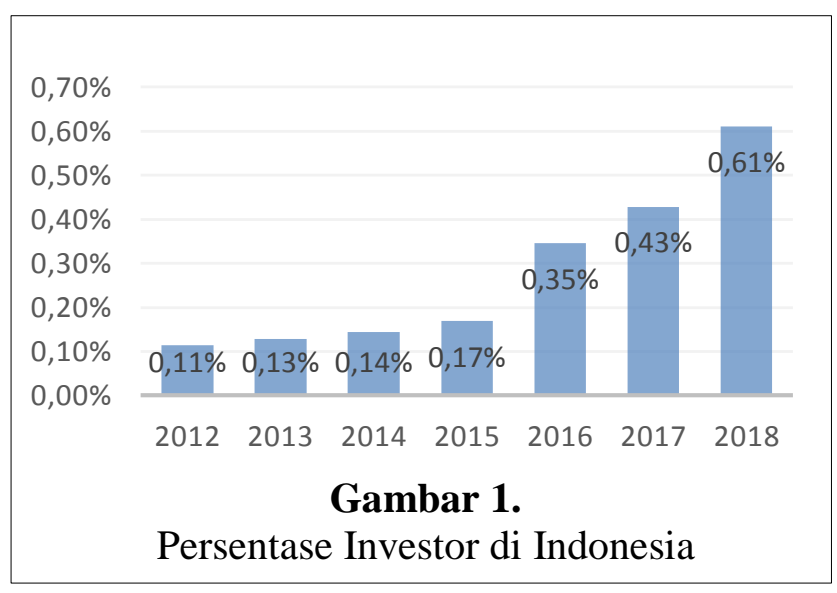

Menurut proyeksi Badan Pusat Statistik (BPS, 2018) jumlah penduduk Indonesia tahun 2018 adalah 265 juta jiwa dan menurut PT Kustodian Sentral Efek Indonesia (KSEI, 2018) jumlah Single Investor Identification (SID) di Indonesia adalah 1.617.367 SID. Jika dibandingkan maka hanya $0,61 \%$ penduduk Indonesia yang menjadi investor di pasar modal. Di Malaysia 12,8\%, Singapura 30\%, dan Tiongkok 13,7\% (Kumparan, 2017). Jumlah Penduduk dan Investor di Indonesia pada tahun 2012 sampai 2018 dapat dilihat pada Tabel 1.

Dari Gambar 1 dapat disimpulkan bahwa rata-rata pertumbuhan persentase jumlah investor di Indonesia pada tahun 2012 sampai 2018 hanya 0,17\% per tahun. Hal ini tentu menjadi perhatian banyak pihak di Indonesia seperti BEI, OJK dan PT KSEI yang harus terus mengeluarkan program-program untuk meningkatkan jumlah investor di Indonesia. Permasalahan ini menjadi fenomena karena negara sebesar Indonesia yang jumlah penduduknya menempati peringkat keempat di dunia, ternyata memiliki jumlah investor yang sangat sedikit yakni dibawah 1\% sampai dengan akhir 2018. Banyak hal yang diduga dapat menjadi faktor yang mendorong naiknya jumlah investor di pasar modal, anatara lain: ekspektasi pengembalian, toleransi risiko, dan efikasi diri.

Investor ketika memutuskan untuk berinvestasi pasti mengharapkan return yang besar dari modal yang disetorkan dan kemudian ekspektasi pengembalian inilah yang kemudian mempengaruhi seseorang memiliki minat untuk berinvestasi saham pada pasar modal. Trisnatio dan Pustikaningsih (2017) pada penelitiannya terhadap mahasiswa 
Fakultas Ekonomi Universitas Negeri Yogyakarta menunjukan hasil bahwa terdapat pengaruh positif ekspektasi return terhadap minat investasi saham. Raditya, Budiartha, dan Suardikha (2014) dalam studi kasusnya pada mahasiswa Magister di Fakultas Ekonomi dan Bisnis Universitas Udayana Bali menunjukan hasil bahwa semakin besar return yang mungkin diperoleh, semakin besar juga minat investor dalam berinvestasi. Hasil tersebut kembali didukung oleh Tandio dan Widanaputra (2016) yang menemukan hasil penelitian yang sama. Maka, apakah faktor return juga mempengaruhi minat investasi mahasiswa Fakultas Ekonomi dan Bisnis Universitas Tarumanagara Jakarta?

Investasi di pasar modal pasti memiliki risiko atau ketidakpastian yang dapat terjadi kapan pun, risiko tersebut antara lain: risiko kerugian dana yang disetorkan (capital loss) karena gejolak dan fluktuasi harga saham, risiko keamanan transaksi jual-beli, risiko investasi pada emiten abal-abal, dan lain-lain. Tentunya setiap orang berbeda-beda dalam tingkat toleransi risiko yang dapat diterima. Investasi apa yang dipilih dan besarnya dana yang diinvestasikan sangat dipengaruhi oleh toleransi investor terhadap risiko (risk tolerance). Investor kemudian dibagi menjadi 3 jenis menurut tingkat toleransinya terhadap risiko, investor yang menyukai risiko (risk seeker), investor yang menghindari risiko (risk averter), dan investor yang mengabaikan risiko (risk indifference) (Wulandari dan Iramani, 2014).

Pada penelitian terdahulu oleh Yuwono (2011) menunjukkan bahwa variabel toleransi risiko berpengaruh pada minat investasi individual. Hal tersebut didukung oleh penelitian Trisnatio dan Pustikaningsih (2017) yang menyatakan bahwa terdapat pengaruh negatif toleransi risiko terhadap minat investasi saham pada mahasiswa FE UNY. Sehingga semakin tinggi toleransi risiko investasi yang dapat diterima maka akan menyebabkan semakin tingginya minat investasi. Namun, ditemukan hasil penelitian yang menyatakan bahwa toleransi risiko tidak mampu mempengaruhi minat mereka untuk berinvestasi saham di pasar modal (Tandio dan Widanaputra, 2016) dalam penelitiannya pada Fakultas Ekonomi dan Bisnis Universitas Udayana Bali. Hal tersebut kemudian menjadi masalah yang perlu diteliti lebih lanjut.

Keberhasilan dan kegagalan dalam berinvestasi tidak selalu disebabkan oleh faktor intelegensia investor, tetapi juga faktor kecerdasan emosional. Salah satunya adalah efikasi diri, yakni keyakinan seseorang mengenai peluangnya untuk berhasil mencapai tugas tertentu (Kreitner dan Kinicki, 2003). Keyakinan investor yang masih lemah akan menyebabkan investor bimbang dalam membuat rencana investasi. Penelitian Akhtar dan Das (2017) menyatakan bahwa tingkat efikasi diri yang lebih tinggi dikaitkan dengan tingkat minat investasi yang lebih tinggi pula, selain itu lebih lanjut dikemukakan juga bahwa efikasi diri sebagai variabel moderasi memperkuat hubungan positif antara risk-taking propensity (kecenderungan mengambil resiko) dengan minat berinvestasi.

Penelitian yang dilakukan oleh Trisnatio dan Pustikaningsih (2017) menemukan pengaruh positif efikasi diri terhadap minat investasi saham pada mahasiswa FE UNY. Namun, penelitian terkait self-efficacy dengan minat investasi masih jarang ditemukan. Efikasi diri lebih umum dijadikan sebagai prediktor minat berwirausaha, padahal menurut Ismail et al. (2017) seseorang yang memiliki efikasi diri yang tinggi dapat membantu mereka mencapai perilaku keuangan yang positif dan mengatasi setiap tantangan terutama dalam hal masalah keuangan. Hagan (2008) juga menyampaikan bahwa financial selfefficacy (FSE) merupakan prediktor signifikan secara statistik untuk minat investasi pasar saham dan pencarian informasi keuangan. Sehingga dapat disimpulkan bahwa pengaruh efikasi diri terhadap minat investasi masih perlu untuk diteliti lebih lanjut. 


\section{KAJIAN TEORI}

Theory of planned behavior (TPB) dikembangkan oleh Icek Ajzen dan Martin Fishbein yang merupakan pengembangan dari theory of reasoned action (TRA). Menurut Ajzen dan Fishbein (1991) attitude toward the behavior merupakan keseluruhan evaluasi seseorang mengenai positif atau negatifnya untuk menampilkan suatu perilaku tertentu. Subjective norm merupakan kepercayaan seseorang mengenai tuntutan dari orang lain yang dianggap penting baginya untuk bersedia menampilkan atau tidak menampilkan suatu perilaku tertentu sesuai dengan tuntutan. Perceived behavioral control adalah persepsi seseorang tentang kemampuannya untuk menampilkan suatu perilaku tertentu.

Pada penelitian ini attitude toward the behavior akan diteliti dengan variabel independen ekspektasi pengembalian. Subjective norm akan diteliti dengan variabel toleransi risiko, dan behavioral control akan diteliti dengan variabel independen efikasi diri.

Kemudian behavior di bidang keuangan dikenal dengan istilah financial management behavior yang didefinisikan sebagai kemampuan seseorang dalam mengatur dana keuangan sehari-hari yang muncul karena besarnya hasrat seseorang untuk memenuhi kebutuhan hidupnya sesuai dengan tingkat pendapatan yang diperoleh (Kholilah dan Iramani, 2013). Menurut Rizkiawati dan Asandimitra (2018) financial management behavior berkaitan dengan proses mengelola keuangan serta proses menguasai penggunaan aset keuangan maupun aset-aset yang lain dengan produktif.

\section{Kaitan Antar Variabel}

1. Hubungan antara Ekspektasi Pengembalian dengan Minat Investasi Saham

Alasan utama orang berinvestasi adalah untuk memperoleh keuntungan. Dalam manajemen investasi, tingkat keuntungan investasi disebut sebagai return. Suatu hal yang sangat wajar jika investor menuntut tingkat return tertentu atas dana yang telah diinvestasikannya. Return yang diharapkan investor dari investasi yang dilakukannya merupakan kompensasi atas biaya kesempatan (opportunity cost) dan resiko penurunan daya beli akibat adanya pengaruh inflasi. Dalam berinvestasi perlu dibedakan antara return yang diharapkan (expected return) dan return yang terjadi (realized return).

Ekspektasi pengembalian adalah harapan dan keinginan investor dalam bentuk keuntungan yang diperoleh di masa mendatang dari kegiatan investasi yang dilakukan di pasar modal. Bagi investor yang rasional, mereka akan mengharapkan return yang tinggi meskipun dengan begitu berarti risiko yang dihadapi juga tinggi. Jadi, faktor ini diperkirakan akan mempengaruhi minat investasi saham.

2. Hubungan antara Toleransi Risiko dengan Minat Investasi Saham

Risiko adalah ketidakpastian, dalam hal ini dapat diartikan tidak mendapatkan apa yang diharapkan atau justru mendapatkan apa yang diharapkan. Risiko biasanya menjadi penghalang bagi orang untuk melakukan investasi, khususnya investasi saham. Investasi saham merupakan instrumen investasi yang memberikan return yang tinggi, namun dengan risiko yang tinggi juga. Setiap orang pada dasarnya memiliki anggapan yang berbeda-beda terhadap risiko. Toleransi risiko adalah jumlah maksimum ketidakpastian yang bersedia diterima seseorang ketika membuat keputusan keuangan, menjangkau hampir setiap bagian kehidupan ekonomi dan sosial dengan tujuan mengejar kekayaan yang lebih besar di masa mendatang.

Pengetahuan yang rendah terhadap pasar modal dapat membuat orang memiliki anggapan yang salah terhadap risiko pada pasar modal. Sebaliknya, investor yang sudah 
masuk ke pasar modal tentu sudah mengerti berbagai risiko yang akan dihadapi dan dapat memilih keputusan yang tepat untuk meminimalisir risiko tersebut. Faktor ini diperkirakan mampu mempengaruhi minat investasi saham. Seperti pada penelitian Yuwono (2011) yang menemukan bahwa risiko menjadi salah satu faktor yang paling berpengaruh pada minat investasi saham.

3. Hubungan antara Efikasi Diri dengan Minat Investasi Saham

Efikasi diri adalah keyakinan dan kepercayaan orang tentang kemampuannya sendiri untuk menghasilkan tingkat kinerja yang ditentukan, yang mempengaruhi aktivitas kehidupannya. Setiap individu memiliki efikasi diri yang berbeda-beda pada situasi yang berbeda tergantung pada kemampuan yang menuntut, kehadiran orang lain, keadaan fisiologis dan emosional. Efikasi diri mempengaruhi seseorang sehingga dapat mendorong perilaku yang menghasilkan pencapaian yaitu minat untuk melakukan investasi saham di pasar modal. Berdasarkan pengertian tentang efikasi diri, efikasi diri diperkirakan dapat mempengaruhi minat seseorang investasi saham.

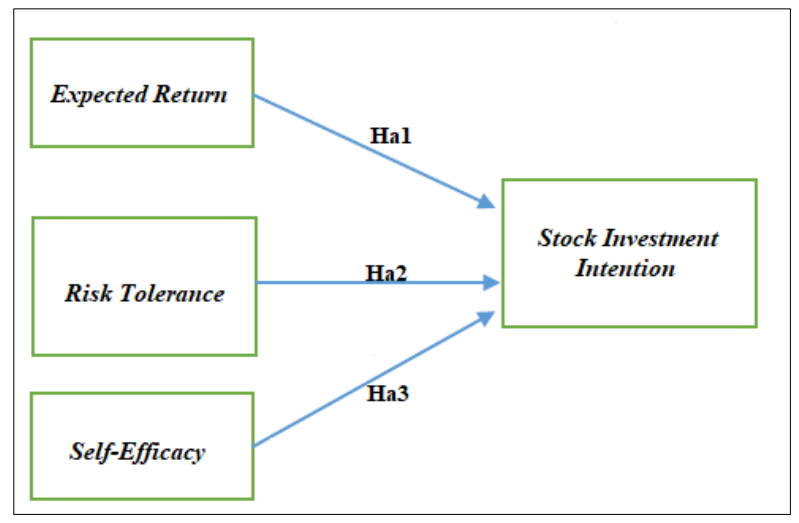

Gambar 2.

Kerangka Pemikiran

Hipotesis yang digunakan dalam penelitian ini adalah sebagai berikut:

Ha1: Terdapat pengaruh positif signifikan ekspektasi pengembalian terhadap minat investasi saham

Ha2: Terdapat pengaruh positif signifikan toleransi risiko terhadap minat investasi saham

Ha3: Terdapat pengaruh positif signifikan efikasi diri terhadap minat investasi saham

\section{METODOLOGI}

Dalam penelitian ini menggunakan 100 sampel yang merupakan mahasiswa aktif di Fakultas Ekonomi dan Bisnis Universitas Tarumanagara dan usianya diatas 17 tahun. Metode pengumpulan sampel non-probability berjenis purposive sampling.

Penelitian ini menggunakan instrumen penelitian berupa lembaran kuesioner yang berisi pernyataan terstruktur untuk dijawab oleh responden yang digunakan untuk mengukur ekspektasi pengembalian, toleransi risiko, efikasi diri dan minat investasi saham. Data yang digunakan dalam penelitian ini adalah data primer yang diperoleh dari responden melalui kuesioner online yang dibuat menggunakan Google Form.

Penelitian ini terdiri dari variabel independen dan dependen. Pada penelitian ini terdapat 3 variabel independen, yakni ekspektasi pengembalian, toleransi risiko, dan efikasi diri serta 1 variabel dependen dependen yakni minat investasi saham. Masing-masing variabel memiliki beberapa indikator dan diukur dengan menggunakan skala likert dengan besarnya skor berkisar antara 1-5.

Penelitian ini menggunakan metode PLS-SEM untuk analisis data dengan pertimbangan bahwa data tidak diharuskan besar (Hair et al., 2011). Pengolahan data dengan metode PLS-SEM akan dilakukan dengan menggunakan software SmartPLS versi 3.2.8. 


\section{HASIL ANALISIS DATA}

Hasil analisis data dengan bantuan software SmartPLS akan diuraikan di bagian ini termasuk hasil pengujian pada inner model (model struktural), pengujian goodness of fit model (GoF), serta pengujian hipotesis (t-Test). Inner model evaluation terdiri atas coefficient of determination $\left(\mathrm{R}^{2}\right)$, predictive relevance $\left(\mathrm{Q}^{2}\right)$; path coefficients; dan effect sizes $\left(\mathrm{f}^{2}\right)$.

1. Pengujian Model Struktural (Inner Model Evaluation)

a. Coefficient of Determination $\left(\mathrm{R}^{2}\right)$

Dari Tabel 2 dapat terlihat bahwa sebesar 67\% variabel minat investasi saham dapat dijelaskan oleh variabel independen. Sedangkan sisanya sebesar 33\% dijelaskan oleh variabel lainnya di luar penelitian ini. Menurut Hair et al. (2011), nilai koefisien determinasi tersebut digolong dalam pengaruh moderate.

Tabel 2. Hasil Coefficient of Determination

Sumber: Output SmartPLS 3.2.8

\begin{tabular}{|c|c|}
\hline Variabel & $\mathrm{R}^{2}$ \\
\hline Stock Investment Intention & 0,67 \\
\hline
\end{tabular}

b. Predictive Relevance $\left(\mathrm{Q}^{2}\right)$

Variabel eksogen dinyatakan dapat memprediksi variabel endogen dengan baik jika nilai $\mathrm{Q}^{2}$ lebih besar dari nol (Hair et al., 2012). Berdasarkan hasil nilai $\mathrm{Q}^{2}$ yang diperoleh tersebut, dapat dinyatakan bahwa variabel independen dapat memprediksi variabel dependen dengan baik.

Tabel 3. Hasil Predictive Relevance

\begin{tabular}{|c|c|}
\hline Variabel & $\mathrm{Q}^{2}$ \\
\hline Stock Investment Intention & 0.36 \\
\hline
\end{tabular}

Sumber: Output SmartPLS 3.2.8

c. Path Coefficients

Metode bootstrapping menghasilkan nilai path coefficients, $\mathrm{t}$-statistics juga $\mathrm{p}$-values untuk masing-masing variabel independen terhadap variabel dependen. Pada penelitian ini, seluruh variabel independen merupakan prediktor positif terhadap variabel dependen. Dengan demikian, persamaan untuk penelitian ini adalah $\mathrm{SII}=0,52 \mathrm{ER}+0,44 \mathrm{RT}+0,11$ SE.

Tabel 4. Hasil Bootstrapping Akhir

\begin{tabular}{|c|c|c|c|}
\hline \multirow{2}{*}{ Variabel } & \multicolumn{3}{|c|}{ Stock Investment Intention } \\
\cline { 2 - 4 } & Path Coefficients & $\mathrm{t}$-stat & $\mathrm{p}$-values \\
\hline Expected Return & 0.52 & 5.267 & 0 \\
\hline Risk Tolerance & 0.44 & 4.594 & 0 \\
\hline Self-Efficacy & 0.11 & 1.487 & 0.13 \\
\hline
\end{tabular}

Sumber: Output SmartPLS 3.2.8

d. Effect Sizes $\left(\mathrm{f}^{2}\right)$

Hair et al. (2012) menggolongkan efek dari variabel prediktor menjadi 3 kategori, dimana nilai 0,02 menunjukkan efek kecil, nilai 0,15 menunjukkan efek moderate, dan nilai 0,35 menunjukkan efek besar. Nilai effect sizes pada penelitian ini disajikan pada Tabel 5 . 
Pada penelitian ini, variabel ekspektasi pengembalian memiliki efek besar $(0,69)$, variabel toleransi risiko memiliki efek besar $(0,51)$, variabel efikasi diri memiliki efek kecil $(0,03)$ terhadap minat investasi saham.

Tabel 5. Hasil Effect Sizes

\begin{tabular}{|c|c|}
\hline Variabel & Stock Investment Intention \\
\hline Expected Return & 0.69 \\
\hline Risk Tolerance & 0.51 \\
\hline Self-Efficacy & 0.03 \\
\hline
\end{tabular}

Sumber: Output SmartPLS 3.2.8

\section{Hasil Pengujian Goodness of Fit Model}

Goodness of fit index dihitung dengan mengakar-kuadratkan perkalian nilai average communality index dan average $\mathrm{R}^{2}$. Nilai $\overline{A V E}$ sebesar $\left(\overline{A V E}=\frac{0,53+0,59+0,53+0,6}{4}\right)$ dan nilai $\overline{R^{2}}$ sebesar 0,67 (Tabel 2). Setelah mendapatkan nilai yang dibutuhkan, maka nilai GoF index dapat diperhitungkan secara manual dengan rumus berikut ini:

$$
\begin{gathered}
\mathrm{GoF}=\sqrt{\overline{A V E} \times \overline{R^{2}}}=\sqrt{0,5625 \times 0,67} \\
\mathrm{GoF}=0,613901457890434
\end{gathered}
$$

Dari hasil perhitungan nilai GoF secara manual, nilai GoF yang didapatkan adalah sebesar 0,613901457890434. Berdasarkan kategori GoF menurut Wetzels et al. (2009), model penelitian ini memiliki tingkat ketepatan (goodness of fit) yang tergolong besar/tepat (GoF > 0,36).

3. Hasil Pengujian Hipotesis

Nilai t-statistics ditujukan untuk menguji hipotesis penelitian, dimana hipotesis penelitian dapat diterima apabila nilai t-statistics variabel diatas 1,96 (tingkat signifikansi 5\%) dan p-value kurang dari cut-off value (5\%) menurut Henseler et al. (2009) dan Hair et al. (2011). Nilai t-statistics dan p-value masing-masing hipotesis terlampir pada Tabel 4.

a. Hipotesis 1

Ha1: Terdapat pengaruh positif signifikan ekspektasi pengembalian terhadap minat investasi saham.

Nilai t-statistics untuk hipotesis pertama sebesar 5,267 (t-statistics $>1,96$ ) dan nilai $\mathrm{p}$-value sebesar $0(\mathrm{p}<0,05)$, sehingga hipotesis pertama dapat diterima (tidak ditolak). Dengan demikian, dapat dibuktikan bahwa terdapat pengaruh positif yang signifikan ekspektasi pengembalian terhadap minat investasi saham.

b. Hipotesis 2

$\mathrm{Ha} 2$ : Terdapat pengaruh positif signifikan toleransi risiko terhadap minat investasi saham.

Nilai t-statistics untuk hipotesis pertama sebesar 4,594 (t-statistics $>1,96)$ dan nilai $\mathrm{p}$-value sebesar $0(\mathrm{p}<0,05)$, sehingga hipotesis kedua dapat diterima (tidak ditolak). Dengan demikian, dapat dibuktikan bahwa terdapat pengaruh positif yang signifikan toleransi risiko terhadap minat investasi saham.

c. Hipotesis 3

Ha3: Terdapat pengaruh positif signifikan efikasi diri terhadap minat investasi saham. 
Nilai t-statistics untuk hipotesis pertama sebesar 1,487 (t-statistics $<1,96$ ) dan nilai $\mathrm{p}$-value sebesar 0,13 ( $\mathrm{p}>0,05)$, sehingga hipotesis ketiga tidak diterima (ditolak). Dengan demikian, diketahui bahwa terdapat pengaruh positif tidak signifikan efikasi diri terhadap minat investasi saham.

Tabel 6. Hasil Pengujian Hipotesis

\begin{tabular}{|c|l|c|}
\hline Kode & \multicolumn{1}{|c|}{ Hipotesis } & \multicolumn{1}{|c|}{ Hasil } \\
\hline Ha1 & $\begin{array}{l}\text { Terdapat pengaruh positif signifikan ekspektasi pengembalian } \\
\text { terhadap minat investasi saham. }\end{array}$ & $\begin{array}{c}\text { Tidak } \\
\text { ditolak }\end{array}$ \\
\hline Ha2 & $\begin{array}{l}\text { Terdapat pengaruh positif signifikan toleransi risiko terhadap minat } \\
\text { investasi saham. }\end{array}$ & $\begin{array}{c}\text { Tidak } \\
\text { ditolak }\end{array}$ \\
\hline Ha3 & $\begin{array}{l}\text { Terdapat pengaruh positif signifikan efikasi diri terhadap minat } \\
\text { investasi saham. }\end{array}$ & Ditolak \\
\hline
\end{tabular}

\section{DISKUSI}

1. Pengaruh Ekspektasi Pengembalian terhadap Minat Investasi Saham

Terdapat pengaruh positif signifikan ekspektasi pengembalian terhadap minat investasi saham Mahasiswa S1 Fakultas Ekonomi dan Bisnis Universitas Tarumanagara Jakarta. Sehingga dapat disimpulkan bahwa semakin besar return yang diberikan, akan semakin besar juga minat investasi seseorang pada instrumen investasi saham di pasar modal.

Pada pengukuran ekspektasi pengembalian, indikator yang memiliki pengaruh paling besar adalah "menurut saya investasi di pasar modal memberikan keuntungan yang besar sesuai dengan resiko yang ada." Hasil ini menunjukkan bahwa mahasiswa mengetahui adanya risiko dan menyakini bahwa berinvestasi di pasar modal (saham) memberikan keuntungan yang besar sebagai kompensasinya. Hasil penelitian ini sesuai dengan hasil penelitian-penelitian sebelumnya yang telah dilakukan oleh Trisnatio dan Pustikaningsih (2017) yang menyatakan bahwa ekpektasi return berpengaruh positif terhadap minat investasi saham. Begitu juga dengan Raditya, Budiartha, dan Suardikha (2014) dan Tandio dan Widanaputra (2016) menyatakan bahwa return berpengaruh positif signifikan terhadap minat investasi mahasiswa.

2. Pengaruh Toleransi Risiko terhadap Minat Investasi Saham

Terdapat pengaruh positif signifikan toleransi risiko terhadap minat investasi saham Mahasiswa S1 Fakultas Ekonomi dan Bisnis Universitas Tarumanagara Jakarta. Dari penelitian ini dapat diketahui bahwa semakin tinggi toleransi risiko seseorang maka semakin tinggi minat seseorang untuk berinvestasi saham di pasar modal.

Pada pengukuran toleransi risiko, indikator yang memiliki pengaruh paling besar adalah "saya lebih memilih mengalokasikan kelebihan dana saya untuk berinvestasi saham daripada disimpan dalam bentuk tabungan." Hasil ini menunjukkan bahwa mahasiswa lebih memilih mengalokasikan dana yang dimiliki untuk diinvestasikan seperti saham daripada disimpan dalam bentuk tabungan. Sudah diketahui bersama bahwa bunga yang diberikan bank pada produk tabungan sangatlah kecil dan jumlah saldo yang ada pada tabungan dapat tergerus oleh biaya administrasi bulanan bank. Jika dibandingkan dengan menabung di bank, kegiatan investasi berpotensi untuk mendapatkan keuntungan yang lebih besar. Hasil penelitian ini sesuai dengan hasil penelitian-penelitian sebelumnya yang telah dilakukan 
oleh Trisnatio dan Pustikaningsih (2017) serta Tandio dan Widanaputra (2016) menyatakan bahwa tingkat toleransi terhadap risiko (risk tolerance) berpengaruh positif terhadap minat investasi saham.

3. Pengaruh Efikasi Diri terhadap Minat Investasi Saham

Terdapat pengaruh positif tidak signifikan efikasi diri terhadap minat investasi saham Mahasiswa S1 Fakultas Ekonomi dan Bisnis Universitas Tarumanagara Jakarta. Hasil penelitian ini serupa dengan hasil penelitian Sondari dan Sudarsono (2015) yang menyatakan bahwa efikasi diri tidak menunjukan pengaruh signifikan terhadap minat investasi. Namun pada penelitian Trisnatio dan Pustikaningsih (2017) efikasi diri diketahui berpengaruh positif terhadap minat investasi saham. Akhtar dan Das (2017) juga menemukan bahwa tingkat self-efficacy yang lebih tinggi dikaitkan dengan tingkat minat investasi yang lebih tinggi pula, sehingga terdapat pro dan kontra mengenai pengaruh efikasi diri terhadap minat investasi saham. Setelah mempelajari jawaban dan latar belakang responden, diketahui bahwa mahasiswa secara umum masih bergantung kepada orangnya dalam hal finansial. Hal ini yang kemudian diduga menjadi penyebab pengaruh efikasi diri yang tidak signifikan terhadap minat investasi saham. Adapun hal lain yang juga diduga menjadi penyebabnya adalah kurangnya pengetahuan pasar modal, keahlian berinvestasi, dan tingkat percayaan terhadap instrumen investasi. Hal ini masih perlu diteliti lebih untuk dibuktikan kebenarannya.

\section{PENUTUP}

Berdasarkan analisis data dan pembahasan yang telah dilakukan, maka hasil dari penelitian ini dapat disimpulkan terdapat pengaruh positif signifikan ekspektasi pengembalian dan toleransi risiko terhadap minat investasi saham. Terdapat pengaruh positif tidak signifikan efikasi diri terhadap minat investasi saham. Terkait dengan hasil yang diperoleh dari penelitian ini dengan segala keterbatasannya, maka saran yang dapat diberikan bagi peneliti berikutnya, untuk: memperluas jangkauan wilayah pengambilan sampel serta meningkatkan jumlah sampel agar dapat memperbaiki dan memperkuat penelitian-penelitian sebelumnya dengan semakin beragamnya karakteristik dari sampel penelitian, mengganti variabel toleransi risiko menjadi persepsi terhadap risiko, mengganti variabel efikasi diri menjadi financial self-efficacy, dan mengikutsertakan variabel lainnya dalam penelitian seperti financial literacy, demografi, motivasi, keahlian, kepercayaan pada instrumen investasi dan variabel lainnya. Bagi perusahaan sekuritas, BEI, IJK dan PT KSEI disarankan untuk mengadakan edukasi lebih mendalam terhadap perencanaan keuangan jangka panjang khususnya bagi mahasiswa dalam rangka meningkatkan tingkat financial self-efficacy. Selain itu, juga memberikan edukasi prihal risiko dan return dalam berbagai instrumen investasi di pasar modal agar mahasiswa dalam kegiatan investasinya bersikap rasional dan bertanggungjawab.

\section{DAFTAR PUSTAKA}

Ajzen, I. (1991). The Theory of Planned Behavior. Organizational Behavior and Human Decision Processes, 50(2), 179-211. DOI:10.1016/0749-5978(91)90020-t.

Akhtar, F., Das, N., \& Roy, R. (2017). Entrepreneurial Intention Among Science \& Technology Students In India: Extending The Theory of Planned Behavior. 
International Entrepreneurship and Management Journal, 13(4), 1013-1041. DOI:10.1108/ijbm-08-2017-0167.

BPS (2018). Statistik Indonesia dalam Infografis 2018. Jakarta: Badan Pusat Statistik.

Hagan, D. A. L. (2008). The Role of Self-Efficacy in Stock-Market Participation and Financial Information-Seeking. Tesis. Cornell University: New York.

Hair, J. F., Sarstedt, M., \& Ringle, C.M. (2011). Indeed a Silver Bullet. Journal of Marketing Theory and Practice, 19(2), 139-152. DOI:10.2753/mtp1069-6679190202.

, \& Mena, J. A. (2012). An Assessment of The Use of Partial Least Squares Structural Equation Modeling in Marketing Research. Journal of the Academic Marketing Science, 40, 414-433. DOI:10.1007/s11747-011-0261-6.

Henseler, J., Ringle, C.M. \& Sinkovics, R.R. (2009). The Use of Partial Least Squares Path Modelling in International Marketing. A.dvances in International Marketing, 20, $277-$ 319. DOI:10.1108/S1474-7979.

Ismail, S., Faique, F. A., Bakri, M. H., Zain, Z. M., Idris, N. H., Yazid, Z. A., Daud, S., \& Taib, N. M. The Role of Financial Self-Efficacy Scale in Predicting Financial Behavior. American Scientific Publishers.

Kholilah, N. A. \& Iramani, R.R. (2013). Studi Financial Management Behaviour pada Masyarakat Surabaya. Journal of Business and Banking, 3(1), 69-80.

Kreitner, R. \& Kinicki, A. (2003). Perilaku Organisasi, Dalam: Early Suandy (penterjemah). Jakarta: Salemba Empat.

KSEI (2018). 21 Tahun KSEI: Inovasi Untuk Kenyamanan Transaksi di Pasar Modal. Jakarta: KSEI.

Kumparan (2017). 12,8\% Penduduk Malaysia Sudah Investasi Saham, di RI baru 0,2\%. Retrieved June 1, 2019, from https://kumparan.com/@kumparan news/12-8penduduk-malaysia-sudah-investasi-saham-di-ri-baru-0-2.

Manulife Investor Sentiment Index Asuransi Jiwa Manulife Indonesia. (2016). Asuransi Jiwa Terbaik. (n.d.). Retrieved Oktober 10, 2018, from https://www.manulifeindonesia.com/ManulifeInvestorSentimentIndex/

Raditya, D. T., Budiartha, I. K., \& Suardikha, I. M. S. (2014). Pengaruh Modal Investasi Minimal di BNI Sekuritas, Return, dan Persepsi Terhadap Risiko pada Minat Investasi Mahasiswa, dengan Penghasilan sebagai Variabel Moderasi. E-Jurnal Ekonomi dan Bisnis Universitas Udayana, 3(7), 377-390. ISSN: 2337-3067.

Rizkiawati, N. L. \& Asandimitra, N. (2018). Pengaruh Demografi, Financial Knowledge, Financial Attitide, Locus of Control dan Self-Efficacy Terhadap Financial Management Behavior Masyarakat Surabaya. Jurnal Ilmu Manajemen, 6(3).

Sondari, M. C. \& Sudarsono, R. (2015). Using Theory of Planned Behavior in Predicting Intention to Invest : Case of Indonesia. International Academic Research Journal of Business and Technology, 1(2), 137-141.

Tandio, T. \& Widanaputra, A. A. G. P. Pengaruh Pelatihan Pasar Modal, Return, Persepsi Risiko, Gender, dan Kemajuan Teknologi Pada Minat Investasi Mahasiswa. E-Jurnal Akuntansi Universitas Udayana, 16(3), 2316-2341. ISSN: 2302-8556.

Trisnatio, Y. A. \& Pustikaningsih, A. (2017). Pengaruh Ekspektasi Return, Persepsi Terhadap Risiko, dan Self Efficacy Terhadap Minat Investasi Saham Mahasiswa Fakultas Ekonomi Universitas Negeri Yogyakarta. Jurnal Fakultas Ekonomi.

Wetzels, M., Odekerken-Schröder, G. \& van Oppen, C. (2009). Using PLS Path Modeling for Assessing Hierarchical Construct Models: Guidelines and Empirical Illustration. MIS Quaterly, 33(1), 177-195. DOI:10.2307/20650284. 
Wulandari, D. A. \& Iramani, Rr. (2014). Studi Experienced Regret, Risk Tolerance, Overconfidence, dan Risk Perception pada Pengambilan Keputusan Investasi Dosen Ekonomi. Journal of Business and Banking, 4(1), 55-66.

Yuwono, R. S. (2011). Pengaruh Karakteristik Investor Terhadap Besaran Minat Investasi Saham di Pasar Modal. Tesis. Jakarta: Universitas Indonesia. 